\title{
Effect of detergent on alveolar particle clearance due to large tidal ventilation
}

\author{
J John, P Wollmer, M Dahlbäck, B Jonson
}

\begin{abstract}
Background - It has recently been shown that large tidal volume ventilation accelerates the alveolar clearance of insoluble particles and this may be related to accelerated surfactant evacuation from the alveolus into the airway. The aim of this study was to investigate if the effect of large tidal volume ventilation is modified in an experimental model of surfactant dysfunction.

Methods - Fluorescent latex particles of $0.63 \mu \mathrm{m}$ diameter were administered in aerosol form to 30 rabbits during anaesthesia with thiopentone and mechanical ventilation. Six animals were killed immediately after aerosol administration in order to show the initial deposition of particles. Twenty four animals were divided into two groups and ventilated for three hours with either large tidal volume (mean tidal volume $30 \mathrm{ml} / \mathrm{kg}$ ) or conventional ventilation (mean tidal volume $12.5 \mathrm{ml} / \mathrm{kg}$ ). Six rabbits in each of the two groups were administered either the synthetic detergent dioctyl sodium sulphosuccinate in aerosol form or aerosolised vehicle. After the period of experimental ventilation the lungs were removed and dried in the expanded state. Particles in the alveolar region were counted with fluorescent microscopy in sections of the lung.
\end{abstract}

Results - Compared with the baseline group (mean (SD) 24.8 (9.9)) the count of residual alveolar particles was lower after large tidal volume ventilation in the absence of detergent aerosol (13.2 (6.5)). Particle count after large tidal volume ventilation and detergent treatment $(23 \cdot 3$ (6.4)) was similar to that in the baseline group and to that in the groups exposed to conventional ventilation.

Conclusions - The increase in alveolar clearance of insoluble particles caused by large tidal volume ventilation is inhibited by detergent aerosol. This might be due to reduced stability of the surfactant film after detergent aerosol.

(Thorax 1994;49:147-150)

Retention of inhaled particles for prolonged periods in the pulmonary parenchyma is important in the development of pneumoconiosis. Clearance of insoluble particles from the alveoli is considered to occur over a long time lasting from months to years. The biological processes involved in this slow transport of alveolar particles into the proximal airway include the proximal movement of both the alveolar macrophage and the fluid film lining the alveoli. ${ }^{12}$ We have recently shown that large tidal volume ventilation (LTVV) increases the rate of clearance of insoluble particles from the alveoli. ${ }^{3}$ Increased evacuation of alveolar surfactant into proximal airways ${ }^{45}$ might be important for this accelerated particle clearance during LTVV. The surfactant film is believed to spread from the alveolus to the airway along the surface pressure gradien $t^{6}$ which would transport isolated embedded particles ${ }^{7}$ or phagocytosed particles within macrophages. Impaired film motion or surfactant dysfunction could theoretically lead to prolonged alveolar retention of insoluble particles. The object of this study was to investigate whether surfactant dysfunction affects the accelerated transport of insoluble particles from the alveolus observed during LTVV. The clearance of insoluble fluorescent particles from the alveoli was studied in mechanically ventilated rabbits. The animals were ventilated with large or small tidal volumes, with or without surfactant dysfunction induced by administration of the detergent dioctyl sodium sulphosuccinate in aerosol form. ${ }^{89}$

\section{Methods}

Thirty rabbits of mean (SD) weight $3.0(0.5)$ $\mathrm{kg}$ were randomly divided into five groups of six rabbits each. In the baseline group the animals were killed immediately after particle administration in order to show the initial distribution of particles. Each of the other groups was designated by a composite name which identified the aerosol type and the experimental ventilation pattern as follows: (1) baseline, mean (SD) weight $3.2(0.7) \mathrm{kg}$; (2) control-CV (vehicle aerosol with conventional ventilation), $2.9(0.1) \mathrm{kg}$; (3) control-LTVV (vehicle aerosol with LTVV), $3.2(0.7) \mathrm{kg}$; (4) detergent-CV ( $2 \%$ dioctyl sodium sulphosuccinate with conventional ventilation), $2.9(0.2)$ $\mathrm{kg}$; and (5) detergent-LTVV ( $2 \%$ dioctyl sodium sulphosuccinate with LTVV), $2 \cdot 7$ $(0 \cdot 2) \mathrm{kg}$.

\section{ANAESTHESIA}

Anaesthesia was induced with an intravenous bolus dose of $17.5 \mathrm{mg} / \mathrm{kg}$ thiopentone and maintained with an infusion at the rate of $1.25 \mathrm{mg} / \mathrm{kg} / \mathrm{min}$. The animals underwent tracheostomy and a neuromuscular block during ventilation was maintained with $0.03 \mathrm{mg} / \mathrm{kg}$ 
pancuronium bromide administered half hourly. A femoral artery was cannulated for blood sampling and blood pressure monitoring.

EXPERIMENTAL PROTOCOL

Expired volumes, airway pressures, and blood gases

Airway pressures, expired volume, and arterial blood gas tensions were measured in all animals while being ventilated in the pressure control mode of the Servo Ventilator 900C (Siemens Elema AB, Sweden) at a rate of 40 / min. The ratio of inspiratory to expiratory time was $1: 2$ and the positive end expiratory pressure (PEEP) was $2 \mathrm{~cm} \mathrm{H}_{2} \mathrm{O}$. Inspiratory airway pressure (PINSP) was initially set so that tidal volume (VT) was $10 \mathrm{ml} / \mathrm{kg}$. This mode of ventilation was used during preparation of the animal and during measurements of expired volumes, airway pressures, and blood gases obtained before and after a period of experimental ventilation (see below). Additional measurements were obtained during experimental ventilation. Airway pressure and expired volume were obtained from the pressure and flow transducers of the Servo Ventilator. Compliance of the respiratory system (CRS) was derived as

$$
\text { CrS }=\text { Vt } /(\text { PPAUSE }- \text { PEEP }) / \text { weight }
$$

where PPAUSE was the airway pressure at the end of the post inspiratory pause period.

\section{Fluorescent particle administration}

A suspension from the same bottle of yellow green latex microspheres (Fluoresbrite carboxylate, Polysciences Inc, USA) with a diameter of $0.63(0.01) \mu \mathrm{m}$ and concentration $3 \times 10^{10}$ particles $/ \mathrm{ml}$ was aerosolised and delivered over 200 volume controlled breaths using an Ultra Vent nebuliser (Mallincrodt Diagnostica, The Netherlands) in conjunction with the Servo Ventilator 900C. The nebuliser was activated during expiration when aerosol was nebulised into the inspiratory line. ${ }^{10}$ The ensuing inspiration transported the particles to the alveoli. The mass median diameter of the primary droplet was $1.07 \mu \mathrm{m}$ as measured at a distance of $1 \mathrm{~cm}$ from the tip of the endotracheal tube by a laser light scattering device (Malvern MasterSizer, Malvern Instruments Ltd, Malvern, UK). During particle administration the ventilator was set at a respiratory rate of $40 / \mathrm{min}$, constant inspiratory flow, inspiratory time $50 \%$, pause time $20 \%$, PEEP $2 \mathrm{~cm} \mathrm{H}_{2} \mathrm{O}$, and $\mathrm{VT} 9 \mathrm{ml} / \mathrm{kg}$ in all animals. This mode was chosen to promote alveolar deposition of particles. ${ }^{10}$ The nebulisation chamber was weighed before and after aerosol administration to determine the weight of fluid nebulised.

The baseline group was killed immediately after aerosol deposition with an overdose of thiopentone.
Detergent and vehicle aerosol administration The dioctyl sodium sulphosuccinate aerosol was prepared as a $2 \%$ solution in a vehicle consisting of equal volumes of ethanol and physiological saline. Twelve animals were given detergent aerosol while the remaining 12 were given vehicle aerosol. The detergent or vehicle aerosols were administered as 200 pressure controlled breaths at a frequency of $40 /$ min, PINSP $13 \mathrm{~cm} \mathrm{H}_{2} \mathrm{O}$ over PEEP, I:E ratio $1: 2$, using the Ultra Vent nebuliser. With this mode of administration approximately $10 \mu \mathrm{l}$ of fluid was deposited in the lungs. Since we have evidence from other experimental situations that the duration of the effect of detergent on surfactant function is limited, aerosol administration was repeated after 90 minutes in both groups.

\section{Experimental ventilation}

After detergent or vehicle aerosol administration the animals were subjected to either LTVV or conventional ventilation (CV) for three hours. CV was pressure controlled ventilation with a PINSP of $13 \mathrm{~cm} \mathrm{H}_{2} \mathrm{O}$ over PEEP and a frequency of $40 / \mathrm{min}$. LTVV was pressure controlled ventilation with PINSP of $25 \mathrm{~cm} \mathrm{H}_{2} \mathrm{O}$ over PEEP and a frequency of 20/ min. PEEP was $2 \mathrm{~cm} \mathrm{H}_{2} \mathrm{O}$ and I:E ratio $1: 2$ during both types of ventilation. A peak inspiratory pressure of $25+2 \mathrm{~cm} \mathrm{H}_{2} \mathrm{O}$ inflates the rabbit lung close to total lung capacity. The tidal volume during $\mathrm{CV}$ was approximately a third of the tidal volume during LTVV. Carbon dioxide $2.5 \%$ was added to the inspired gas during LTVV to maintain arterial $\mathrm{pH}$ at physiological levels. Animals were monitored by arterial blood gas tensions and lung mechanic parameters from the pressure and flow transducers in the Servo Ventilator. After the three hour period the initial mode of ventilation was resumed and measurements of compliance of the respiratory system and blood gases were obtained.

The animals were killed with an overdose of thiopentone and the lungs in all animals were immediately dissected out and dried in the inflated state with an inflating pressure of $25 \mathrm{~cm} \mathrm{H}_{2} \mathrm{O}$ in a microwave oven (Electrolux NF3244, Sweden) for one hour. ${ }^{11}$

\section{Section count}

The right lower lobe was cut into $3 \mathrm{~mm}$ slices and $70 \mu \mathrm{m}$ sections were obtained from these slices with a vibrotome (Biorad, USA). Sections from all animals were randomly coded, pooled, and mixed. The coded sections were viewed at 200 times magnification. With a counting grid mounted in the eyepiece, random samples $250 \mu \mathrm{m} \times 250 \mu \mathrm{m} \times 70 \mu \mathrm{m}$ were selected for counting. Particles were counted separately in the alveoli and alveolar ducts, ${ }^{11}$ and classified as single or clustered particles depending on whether they appeared alone or in aggregates. Up to 200 particles were counted in each section by an observer blind with respect to the origin of the section. 


\section{DATA ANALYSIS}

Intergroup comparisons were performed by the analysis of variance and significance was determined with the Student's $t$ test. Using a general linear models procedure the variance of each variable in section count was apportioned into variance within animal, within group, and between groups. The parameters sequentially monitored within the same animal (lung compliance) were compared by the paired $t$ test.

\section{Results}

The mean (SD) weight of liquid nebulised during administration of fluorescent particles was $0.35(0.03) \mathrm{g}$ in the 30 animals. Similar amounts of liquid were nebulised in the five groups.

There were no significant differences in arterial blood gas measurements between or within groups, before and after the period of experimental ventilation (table 1). Compliance of the respiratory system was similar in all groups before the period of experimental ventilation. After experimental ventilation compliance was reduced $(p<0.05)$ in both groups subjected to large tidal ventilation, whereas it was unchanged in the groups subjected to conventional ventilation.

$\mathrm{PaO}_{2}$ and $\mathrm{PaCO}_{2}$ measured during experimental LTVV was $15 \cdot 7(1 \cdot 6) \mathrm{kPa}$ and $4.0(0 \cdot 8)$ $\mathrm{kPa}$, respectively, whereas during $\mathrm{CV}$ it was $12.0(1.9) \mathrm{kPa}$ and $3.8(0.5) \mathrm{kPa}$, respectively. The mean tidal volume during LTVV was 30 $(4 \cdot 8) \mathrm{ml} / \mathrm{kg}$, whereas that during $\mathrm{CV}$ was 12.5 $(1 \cdot 1) \mathrm{ml} / \mathrm{kg}$.

The total number of particles in the alveoli and ducts were similar in the baseline, detergent-CV, control-CV, and detergent-LTVV groups, but significantly lower $(p<0.05)$ in the control-LTVV group (table 2). The difference in total particle count was mainly the result of a reduced number of alveolar particles in the control-LTVV group, the number of ductal particles not being significantly different between groups. Detergent administration thus significantly modified the effect of LTVV. All experimental groups showed a reduced number of single particles at the alveolar level compared with the baseline group. In most groups this difference was also reflected in the number of single particles in alveoli + ducts. The number of clustered particles in the alveoli+ducts was significantly higher in the detergent-LTVV group than in the baseline group.

\section{Discussion}

Clearance of insoluble particles deposited in the alveolus is known to occur in two phases; ${ }^{2}$ an early phase during the first weeks to months represents clearance into the airways, and the delayed phase over years represents biochemical degradation of particles by biological mechanisms. In a previous study we showed clearance of insoluble particles from the alveolus during LTVV over hours. ${ }^{3}$ The number of clustered - that is, phagocytosed - particles was lower after LTVV than after CV, whereas the number of single particles was similar. We hypothesised that the accelerated clearance could be related to the increased evacuation of surfactant from the alveolus which is associated with LTVV. Two possible mechanisms were considered, one being the active migration of the particle laden alveolar macrophage occurring in association with movement of the surfactant film from the alveolus into the airways during LTVV. The second mechanism involved movement of single particles with the surfactant film into the airways. In this case the rate of phagocytosis of particles must also be assumed to be reduced, as the number of clustered particles was lower. Retarded phagocytosis could be related to surfactant depletion since surfactant is important for macrophage phagocytosis. ${ }^{12}$ The present study was designed to investigate whether the effect of LTVV is modified in an experimental model of surfactant dysfunction.

Table 1 Mean (SD) arterial blood gas tensions, airway pressures, and lung compliance in the five groups before and after the period of experimental ventilation

\begin{tabular}{|c|c|c|c|c|c|c|c|c|c|}
\hline & \multirow[t]{2}{*}{ Baseline } & \multicolumn{2}{|l|}{ Control-CV } & \multicolumn{2}{|c|}{ Detergent-CV } & \multicolumn{2}{|c|}{ Control-LTVV } & \multicolumn{2}{|c|}{ Detergent-LTVV } \\
\hline & & Before & After & Before & After & Before & After & Before & After \\
\hline $\begin{array}{l}\mathrm{PaO}_{2}(\mathrm{kPa}) \\
\mathrm{PacO}_{2}(\mathrm{kPa}) \\
\left.\mathrm{PINSP}_{(\mathrm{cm} \mathrm{H}} \mathrm{O}\right) \\
\text { PMEAN }\left(\mathrm{cm} \mathrm{H}_{2} \mathrm{O}\right) \\
\text { CRS }\left(\mathrm{ml} / \mathrm{cm} \mathrm{H} \mathrm{H}_{2} \mathrm{O} / \mathrm{kg}\right)\end{array}$ & $\begin{array}{c}13 \cdot 2(1 \cdot 3) \\
3.5(0.4) \\
13 \cdot 5(1 \cdot 1) \\
6 \cdot 1(1 \cdot 1) \\
1 \cdot 12(0.31)\end{array}$ & $\begin{array}{c}12.4(2.6) \\
3.8(0.8) \\
12.7(1.4) \\
5.4(0.6) \\
1.31(0.18)\end{array}$ & $\begin{array}{c}11.5(1.3) \\
3.9(0.8) \\
12.3(1.9) \\
5.4(0.5) \\
1.36(0.06)\end{array}$ & $\begin{array}{c}12.5(2.3) \\
3.9(1.0) \\
13.4(2.0) \\
5.9(0.7) \\
1.11(0.16)\end{array}$ & $\begin{array}{c}12 \cdot 5(2 \cdot 0) \\
4 \cdot 0(0 \cdot 8) \\
14 \cdot 1(2 \cdot 6) \\
6 \cdot 0(0 \cdot 7) \\
1.05(0 \cdot 14)\end{array}$ & $\begin{array}{c}12.9(1.4) \\
3.2(0.4) \\
12.8(1.4) \\
5.7(0.6) \\
1.26(0.27)\end{array}$ & $\begin{array}{c}12.3(3.4) \\
3.4(0.6) \\
15.3(1.3) \\
6.3(0.4) \\
1.01(0.24)\end{array}$ & $\begin{array}{c}12.4(1 \cdot 3) \\
4.1(0.3) \\
13.0(1 \cdot 2) \\
5.7(0.6) \\
1.34(0 \cdot 12)\end{array}$ & $\begin{array}{c}11.9(1.5) \\
3.5(0.6) \\
14.7(1.7) \\
6.2(0.4) \\
1.07(0.14)\end{array}$ \\
\hline
\end{tabular}

All measurements were made using the same mode of ventilation. $\mathrm{CV}=$ conventional ventilation; $\mathrm{LTVV}=$ large tidal volume ventilation; $\mathrm{PaO}=$ partial pressure of $\mathrm{O}_{2}$ in arterial blood; $\mathrm{PaCO}_{2}=$ partial pressure of $\mathrm{CO}_{2}$ in arterial blood; PINSP = inspiratory airway pressure; PMEAN $=$ mean airway pressure; CRS $=$ compliance of the respiratory system.

Table 2 Mean (SD) number of particles per unit area $(250 \times 250 \mu m)$ in the histological section

\begin{tabular}{|c|c|c|c|c|c|c|c|c|c|}
\hline & \multicolumn{3}{|l|}{ Alveoli $+d u c t$} & \multicolumn{3}{|c|}{ Alveolar duct } & \multicolumn{3}{|l|}{ Alveoli } \\
\hline & Total & Single & Clustered & Total & Single & Clustered & Total & Single & Clustered \\
\hline $\begin{array}{l}\text { Baseline } \\
\text { Control-CV } \\
\text { Detergent-CV } \\
\text { Detergent-LTVV } \\
\text { Control-LTVV }\end{array}$ & $\begin{array}{l}24.8(9.9)^{* *} \\
23.4(6 \cdot 3)^{*} \\
27 \cdot 1(5 \cdot 7)^{* *} \\
23 \cdot 3(6 \cdot 4)^{*} \\
13 \cdot 2(6 \cdot 5)\end{array}$ & $\begin{array}{l}16 \cdot 6(5 \cdot 4) \\
10 \cdot 8(2 \cdot 1) \dagger+ \\
12 \cdot 6(2 \cdot 4) \\
12 \cdot 5(1 \cdot 9) \dagger \\
9 \cdot 2(3 \cdot 6)++\dagger\end{array}$ & $\begin{array}{l}8 \cdot 3(6 \cdot 8) \\
12 \cdot 7(4 \cdot 5)^{* *} \\
14 \cdot 4(3 \cdot 6)^{* * *} \dagger \\
10 \cdot 8(3 \cdot 0)^{*} \\
4 \cdot 0(2 \cdot 8)\end{array}$ & $\begin{array}{l}2.3(0.9) \\
3.0(0.8) \\
3.1(0.6) \\
3.2(0.8) \\
2.9(0.8)\end{array}$ & $\begin{array}{l}1.8(1.0) \\
1.9(0.4) \\
2 \cdot 2(0.6) \\
2.6(0.5) \\
2.3(0.8)\end{array}$ & $\begin{array}{l}0.5(0.4) \\
1.1(0.6) \\
0.9(0.4) \\
0.6(0.4) \\
0.6(0.4)\end{array}$ & $\begin{array}{l}22 \cdot 5(9 \cdot 4)^{* *} \\
20 \cdot 5(5 \cdot 9)^{*} \\
23 \cdot 9(5 \cdot 2)^{* * *} \\
20 \cdot 1(4 \cdot 6)^{*} \\
10 \cdot 3(6 \cdot 5)\end{array}$ & $\begin{array}{c}14 \cdot 8(5 \cdot 0) \\
8 \cdot 8(1.9) \dagger \dagger \\
10 \cdot 4(2 \cdot 0) \dagger \\
9 \cdot 9(1 \cdot 9) \dagger \\
7 \cdot 0(3 \cdot 9) \dagger+\dagger\end{array}$ & $\begin{array}{l}7 \cdot 7(6 \cdot 6) \\
11 \cdot 6(4 \cdot 1)^{* *} \\
13.5(3 \cdot 4)^{* * *} \\
10 \cdot 2(2 \cdot 8)^{* *} \\
3.4(2 \cdot 8)\end{array}$ \\
\hline
\end{tabular}

$\mathrm{p}<0.05 v$ control-LTVV group; ${ }^{* *} \mathrm{p}<0.01 v$ control-LTVV group; ${ }^{* * *} \mathrm{p}<0.001 v$ control-LTVV group.

$\dagger \mathrm{p}<0.05 v$ baseline group; $\dagger+\mathrm{p}<0.01 v$ baseline group; $+\dagger+\mathrm{p}<0.001 v$ baseline group. 
Surfactant dysfunction was induced by administration of aerosolised detergent. The model has been characterised by Nieman and Bredenberg who showed that, after detergent administration, the surface activity of lung extracts is greatly reduced and the minimal surface tension achieved during film compression is increased. ${ }^{9}$ This conforms to observations of reduced surface activity seen when detergent is added to lung lavage fluid in vitro (Lachmann and Wollmer, unpublished observations). Impaired surfactant function has also been shown after interaction of oleic acid with the surfactant layer, when the surfactant film is relatively fluid and collapses easily during dynamic compression. ${ }^{13}$ Alveolar film collapse due to an inability to withstand compression may reduce surfactant extrusion from the alveoli during LTVV.

Particles deposited in the alveolus are wetted by the surface active film ${ }^{7}$ and submerged in the fluid film. The ability of the film to wet particles is largely due to the very low surface tension achieved by the interfacial film, especially at end expiration. Thus, even particles difficult to wet are fully coated with surfactant after deposition. ${ }^{7}$ The surfactant covering the particles will have the hydrophilic pools directed outwards and create a surface which will be attracted to the interfacial film. Particles could thus be dragged with the film motion towards the airways. Detergent increases the minimum surface tension of the interfacial film ${ }^{9}$ and may thus diminish the ability of the film to wet insoluble particles, which could reduce the efficiency by which the particles are transported with the film. Latex particles, however, are relatively easy to wet and, if the enhanced particle clearance during LTVV is due to accelerated clearance of single particles, the mechanism is likely to be reduced motion of the surface film rather than reduced wetting of particles.

Clustering, which indicates phagocytosis, ${ }^{13}$ was seen to an equal degree in the detergentLTVV, detergent-CV, and control-CV groups. Phagocytosis occurred to the same degree in the detergent-LTVV group as in the groups with $\mathrm{CV}$ where there was a large number of particles. Large numbers of clusters in the detergent-LTVV group indicated that LTVV does not inhibit macrophage phagocytosis, nor does detergent appear to inhibit phagocytosis. Increased clearance of single particles in combination with retarded phagocytosis seems less probable in this context.
Present observations instead lend added credence for facilitated migration of particle laden macrophages as the mechanism for particle clearance during LTVV. However, other models of explanation are still possible. One may, for example, speculate that detergent influences the properties of surfactant related proteins which are of importance in the migration of the macrophage. ${ }^{14}$

In conclusion, LTVV accelerates clearance of alveolar particles. The clearance mechanism is inhibited by detergent. Inhibition of clearance during surfactant dysfunction makes it likely that the clearance mechanism requires a functionally intact surfactant layer. The mechanism of particle clearance during LTVV mostly involves facilitated migration of the particle laden alveolar macrophage in response to the proximal motion of the surfactant film.

The authors wish to thank Tore Persson for help in statistical analysis and Maj-Britt Johansson and Bjorn Drefeldt for technical assistance. This work was supported by the Swedish Medical Research Council (Nos 4732, 10841, and 2872), the Swedish Heart Lung Foundation, and the Medical Faculty of Lund.

1 Sorokin SP, Brain JD. Pathway of clearance in mouse lungs exposed to iron oxide aerosols. Anat Rec 1974;181:581626

2 Lippmann M, Yeates DB, Albert RE. Deposition, retention and clearance of inhaled particles. $\mathrm{Br} F$ Ind $\mathrm{Med}$ $1980 ; 37: 337-62$

3 John J, Wollmer P, Dahlbäck M, Luts A, Jonson B. Tidal volume and alveolar clearance of insoluble particles. $f$ Appl Physiol 1994;76 (in press).

4 Faridy EE. Effect of ventilation on movement of surfactan in airways. Respir Physiol 1976;27:323-34

5 Massaro GD, Massaro D. Morphologic evidence that large inflations of the lung stimulate secretion of surfactant. $A m$ Rev Respir Dis 1983;127:235-6.

6 Mendenhall RM. Surface spreading of lung alveolar surfactant. Respir Physiol 1972;16:175-8.

7 Schurch S, Gehr P, Im Hof V, Geiser M, Green F. Surfactant displaces particles toward the epithelium in airways and alveoli. Respir Physiol 1990;80:17-32.

8 Evander E, Wollmer P, Jonson B. Pulmonary clearance of inhaled ${ }^{99 \mathrm{~m}}$ Tc-DTPA: effect of the detergent dioctyl sodium sulfosuccinate in aerosol. Clin Physio 1988;8:105-11.

9 Nieman GF, Bredenberg CE. High surface tension pulmonary edema induced by detergent aerosol. $7 \mathrm{Appl}$ Physiol 1985;58:129-36.

10 Dahlbäck MP, Wollmer P, Drefeldt B, Jonson B. Controlled aerosol delivery during mechanical ventilation. $\mathscr{f}$ Aer Med 1989;2:339-47.

11 Zeltner TB, Sweeney TD, Skornik WA, Feldman HA, Brain JD. Retention and clearance of $0.9 \mu \mathrm{m}$ particles inhaled by hamsters during rest or exercise. $\mathcal{f} A p p$ Physiol 1991;70:1137-45.

12 Tenner AJ, Robinson SL, Borchelt J, Wright JR. Human pulmonary surfactant protein (SP-A), a protein structurally homologous to $\mathrm{Clq}$, can enhance $\mathrm{FcR}$ - and $\mathrm{CR} 1$ mediated phagocytosis. I Biol Chem 1989;264:13923-8.

13 Hall SB, Zhong Lu R, Eenkitaraman AR, Hyde RW, Notter RH. Inhibition of pulmonary surfactant by oleic acid: mechanisms and characteristics. $尹$ Appl Physiol acid: mechanisms

14 Hoffman RM, Claypool WD, Katyal SL, Singh G, Rogers $\mathrm{RM}$, Dauber JH. Augmentation of rat alveolar macrophage migration by surfactant protein. Am Rev Respir Dis 1987;135:1358-62. 